\title{
A DIMENSÃo PENTECOSTAL DA REPRESENTAÇ̃̃o PARLAMENTAR NA BAIXADA FLUMINENSE/RJ
}

\author{
THE PENTECOSTAL DIMENSION OF PARLIAMENTARY REPRESENTATION IN \\ BAIXADA FLUMINENSE / RJ
}

\section{LA DIMENSIÓN PENTECOSTAL DE LA REPRESENTACIÓN PARLAMENTARIA EN LA BAIXADA FLUMINENSE / RJ}

Gilberto Polastreli Rodolfo ${ }^{1}$ https://orcid.org/0000-0003-3850-6296

\begin{abstract}
${ }^{1}$ Doutorando do Programa do Pós-graduação em Geografia (PPGEO) da Universidade do Estado do Rio de Janeiro (UERJ). Bacharel em Geografia pela Universidade Federal do Rio de Janeiro (UFRJ). Mestre em Geografia pela Universidade do Estado do Rio de Janeiro (UERJ). Professor Titular do Colégio Pedro II (RJ). E-mail: gpolastreli@yahoo.com.br
\end{abstract}

\section{RESUMO}

Inserido num contexto de notável conservadorismo político e religioso no Brasil atual que marca o governo de Jair Bolsonaro, o presente artigo põe em debate o avanço de um ativismo evangélico/pentecostal como força constitutiva de poder político na representação parlamentar da Baixada Fluminense/RJ. O exame quantitativo e qualitativo das leis foi a metodologia empregada para descortinar o imbricamento explícito entre política e religião na consecução de uma representação parlamentar direcionada à consolidação de uma "consciência" evangélica estruturadora da sociedade e do território da região de estudo.

Palavras-chave: Política. Religião. Leis.

\begin{abstract}
Inserted in a context of remarkable political and religious conservatism in Brazil today that marks the government of Jair Bolsonaro, this article discusses the advance of an evangelical/Pentecostal activism as a constitutive force of political power in the parliamentary representation of Baixada Fluminense / RJ. The quantitative and qualitative examination of the laws was the methodology used to reveal the explicit overlap between politics and religion in the achievement of a parliamentary representation aimed at the consolidation of an evangelical "conscience" structuring society and the territory of the study region.
\end{abstract}

Keywords: Politics. Religion. Laws. 


\section{RESUMEN}

Insertado en un contexto de notable conservadurismo político y religioso en Brasil hoy que marca el gobierno de Jair Bolsonaro, este artículo discute el avance de un activismo evangélico/pentecostal como fuerza constitutiva del poder político en la representación parlamentaria de Baixada Fluminense / RJ. El examen cuantitativo y cualitativo de las leyes fue la metodología utilizada para develar la superposición explícita entre política y religión en el logro de la representación parlamentaria orientada a consolidar una "conciencia" evangélica que estructura la sociedad y el territorio de la región de estudio.

Palabras clave: Política. Religión. Leyes.

\section{INTRODUÇÃO}

É provável que a palavra política seja uma das mais polêmicas e controversas de todo o léxico da língua portuguesa, além daquela que mais acarrete discussões acaloradas tanto no cotidiano popular quanto nos círculos acadêmicos e intelectuais hodiernamente. Tendo como caminho de investigação e pesquisa o imbricamento da política com território e tendo a Geografia Política como campo nevrálgico de interesse nas presentes linhas, o artigo em tela tem a proposição de abordar o tema da representação parlamentar e seus vínculos indissociáveis com o território, tendo como escopo territorial de análise a Baixada Fluminense/RJ, e eixo temático o papel e a influência crescente do exercício parlamentar pentecostal na arena política representativa da supracitada região.

A Baixada Fluminense/RJ é composta por treze municípios (mapa 1) de acordo com a Secretaria de Desenvolvimento da Baixada e da Região Metropolitana (SEDEBREM), sendo eles por ordem alfabética: Belford Roxo, Duque de Caxias, Guapimirim, Itaguaí, Japeri, Magé, Mesquita, Nilópolis, Nova Iguaçu, Paracambi, Queimados, São João de Meriti e Seropédica.

Tradicionalmente, a Baixada Fluminense/RJ foi a partir da segunda metade do século XX até fins da década de 1970, interregno temporal de crescente expansão da atividade econômica no município do Rio de Janeiro, um reservatório de expressiva mão-de-obra que se deslocava através da Estrada de Ferro D. Pedro II para a capital para trabalhar ou estudar, constituindo-se em cidades-dormitórios ${ }^{2}$. Malgrado este movimento ainda represente ainda a realidade de milhares de trabalhadores que moram nos municípios da Baixada Fluminense,

2 Designação usada para se referir a aglomerados urbanos surgidos nos arredores de uma grande cidade tipicamente para servir de moradia a trabalhadores da cidade-núcleo da região. Geralmente, a divisão entre subúrbios e cidades-dormitórios é imprecisa, devido à conurbação das cidades. 
este fato já foi relativamente alterado nos dias atuais, uma vez que os movimentos pendulares envolvendo o mercado de trabalho encontram-se significativamente dentro dos próprios municípios ou entre eles.

A Baixada Fluminense constituiu-se, por conseguinte, seja pelo baixo preço das moradias ou pela relativa facilidade de acesso à capital, em "cidades-dormitórios", concentrando grande contingente populacional que trabalhava na capital do Rio de Janeiro. No pensamento de Figuerêdo:

a região em tela se configurava numa expansão urbana acentuada que se direcionou pelo eixo ferroviário e deu origem a uma periferia próxima ao núcleo do Rio de Janeiro; Além de ter um papel importante perante a cidade do Rio de Janeiro, que foi o de absorver trabalhadores no auge do movimento migratório, tendo o fenômeno da periferização como sua maior especificidade”. (FIGUERÊDO 2004, p. 15).

\section{Municípios da Baixada Fluminense (Composição Oficial)}

Estado do Rio de Janeiro - 2020

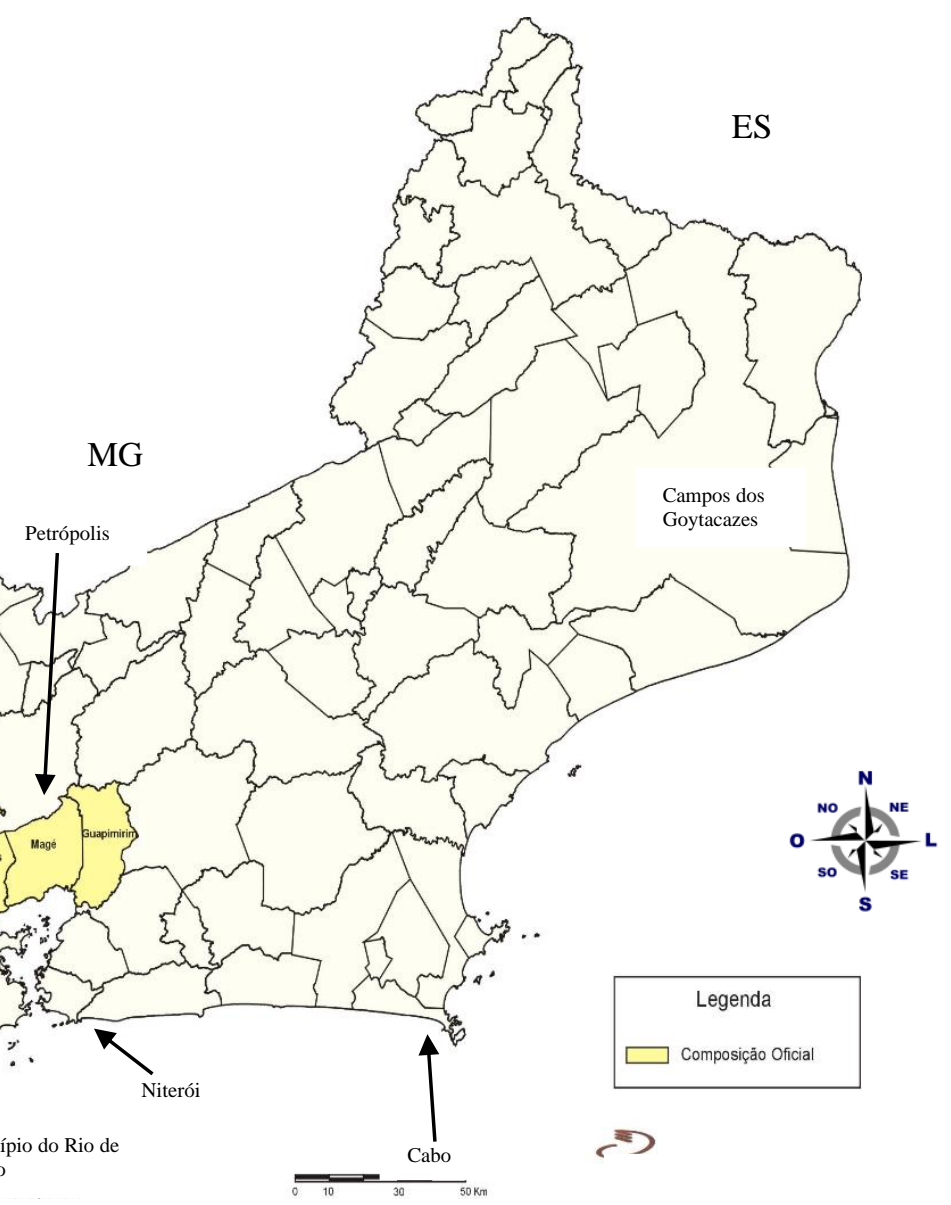

Fonte: SEDEBREM (Secretaria de Desenvolvimento da Baixada e Região Metropolitana). Organizado pelo autor, 2014. 
Nesse contexto, verifica-se a importância da questão populacional da Baixada Fluminense/RJ (tabela 1). Com seus 3. 652.147 de habitantes ${ }^{3}$, a supracitada região representa cerca de $58 \%$ dos residentes da capital fluminense $\left(6.320 .446\right.$ habitantes $\left.^{4}\right)$, núcleo metropolitano com o qual mantém intensamente uma rede de diversos fluxos como o de trabalhadores pendulares destacado alhures. Já em relação ao estado do Rio de Janeiro, a população da região de análise nas presentes linhas equivale a quase um quarto $(23,8 \%)$ de todo contingente populacional fluminense, já que esta soma 15.989 .929 habitantes ${ }^{5}$. Só à guisa de exemplificação, São João de Meriti com uma densidade demográfica de 13.024, ocupa a segunda posição em todo país em termos de habitantes por quilômetro quadrado, só perdendo para o município paulista de Taboão da Serra ${ }^{6}$ com seus 14.058 de densidade demográfica.

Tabela 1 - População Residente, Área, Densidade Demográfica e PIB segundo os municípios da Baixada

\begin{tabular}{|c|c|c|c|}
\hline \multicolumn{4}{|c|}{ Fluminense } \\
\hline Municípios & $\begin{array}{c}\text { População } \\
\text { (2010) }\end{array}$ & $\begin{array}{c}\text { Área Total } \\
\left(\mathrm{Km}^{2}\right)\end{array}$ & $\begin{array}{c}\text { Densidade } \\
\text { demográfica }\end{array}$ \\
\hline Belford Roxo & 469.932 & 77,815 & 6.031 \\
\hline Duque de Caxias & 855.048 & 467,619 & 1.828 \\
\hline Guapimirim & 51.483 & 360,766 & 142 \\
\hline Itaguaí & 109.091 & 275,867 & 395 \\
\hline Japeri & 95.492 & 81,871 & 1.166 \\
\hline Magé & 227.322 & 388,496 & 585 \\
\hline Mesquita & 168.376 & 39,062 & 4.310 \\
\hline Nilópolis & 157.425 & 19,393 & 8.117 \\
\hline Nova Iguaçu & 796.257 & 521,247 & 1.527 \\
\hline Paracambi & 47.124 & 179,680 & 262 \\
\hline Queimados & 137.962 & 75,695 & 1.822 \\
\hline São João de Meriti & 458.673 & 35,216 & 13.024 \\
\hline Seropédica & 78.186 & 283,762 & 275 \\
\hline Total & 3.652 .147 & $2.806,489$ & - \\
\hline
\end{tabular}

Fonte: IBGE (Censo 2010). Organizado pelo autor, 2020.

Na cena política, a Baixada Fluminense historicamente constituiu-se numa ampla arena de embates entre grupos e famílias com grande identidade territorial estritamente delimitada. Tal peculiaridade é visivelmente percebida hodiernamente e a região seja um dos

\footnotetext{
${ }^{3}$ IBGE, 2010.

${ }^{4}$ IBGE, 2010.

${ }^{5}$ IBGE, 2010.

${ }^{6}$ IBGE, 2010
} 
mais notórios casos de todo o Brasil em que, como ratifica Simões (2006, p. 254), o "jogo político obedece a uma razão não ideológica, sendo mais comum a base personalista calcada no carisma, amizade e numa rede clientelista dos candidatos com suas bases eleitorais territorialmente delimitadas". Nessa conjuntura, é notório a influência e o peso do "familismo" nos parlamentos municipais, isto é, o poder político que se perpetua na passagem de cargos eletivos de "pai para filho" mais usualmente ou na transferência para outros componentes da mesma família.

Numa região onde as carências são extremas e as demandas emergenciais da população mais pobre são latentes, a política e a representação parlamentar tire proveito desta situação num imenso mercado eleitoral praticamente restrito a dois grupos antagônicos ou pseudo-adversários, dependendo das coligações e interesses do momento, enraizados territorialmente nos municípios ${ }^{7}$. Nesta perspectiva, o caso da política na Baixada Fluminense respeita uma ordem peremptoriamente territorial e se conecta profundamente com uma influência parlamentar religiosa (evangélica/pentecostal) como será explicado adiante.

O binômio religião-política, inserido no destaque que o ativismo político pentecostal tem nos dias atuais na atuação parlamentar, faz-se asseverar tanto em conformidade com Selman (2019) em sua obra acerca das razões do crescimento do pentecostalismo e do neopentecostalismo na América Latina; passando por Ramos e Zacarias (2020) que esmiúça os projetos de poder de segmentos neopentecostais no Brasil; como em Mariano (2015) o qual traduz a ocupação evangélica na esfera pública brasileira, uma subversão à laicidade do Estado derivado do aumento significativo da sua influência sobre as políticas públicas, destacando que na representação parlamentar na Baixada Fluminense/RJ, há no conjunto total de leis aprovadas em plenário quantidade expressiva de expedientes legislativos que fazem menção a apoios políticos concernentes à existência e funcionamento institucional de entidades religiosas pentecostais e neopentecostais.

Para tal processo de operacionalização e como metodologia aplicada à edificação do trabalho em pauta, foram feitos os levantamentos das leis aprovadas em plenário (legislatura 2017-2020) e sua sistematização em 12 grandes temas para toda a Baixada Fluminense/RJ nos seus 13 municípios, atestando o trabalho parlamentar desde o funcionamento da "máquina administrativa" até as leis que asseguram a consecução de políticas públicas efetivas ao

\footnotetext{
${ }^{7}$ É praticamente inaceitável pela base política local, independente do grupo a que pertence, candidatos não plenamente identificados com a Baixada Fluminense e, mais precisamente, com o município em que se constituirá o pleito. Só para dar um exemplo, Lindbergh Farias, nome conhecido nacionalmente, mas sem vínculo territorial com a baixada, sofreu resistência a sua candidatura dentro de seu próprio partido (PT), sendo denominado pejorativamente pelos seus adversários de "forasteiro".
} 
exercício da cidadania. Não obstante, para fins de respeito as normas protocolares deste artigo de obediência ao tamanho do texto, foi destacado com mais ênfase o segundo maior município da região em termos econômicos e demográficos: Nova Iguaçu. Será almejado demonstrar como o parlamento deste ente municipal respeita uma lógica de apropriação política evangélica/pentecostal nos seus expedientes legislativos.

Isto posto, e como as igrejas que compõem a arena evangélica são de origens históricas distintas e de um sistema organizacional complexo que envolveu grandes reagrupamentos e fusões, mas, sobretudo, dissidências, buscar-se-á conjecturar brevemente nas linhas que se seguem as principais correntes do pentecostalismo no Brasil, uma vez que a metodologia aplicada neste artigo, a influência pentecostal no exercício parlamentar através do exame qualitativo e quantitativo das leis aprovadas em plenário, vai apresentar leis sancionadas que contemplam os interesses organizacionais de entidades religiosas de diferentes matizes do pentecostalismo.

\section{AS “TRÊS ONDAS" DO PENTECOSTALISMO BRASILEIRO: BREVE RECORTE HISTÓRICO}

Tendo como substrato teórico-conceitual os trabalhos de Mariano (2005), Freston (2006), Cipriani (2020), Ramos e Zacarias (2017) e Sélman (2019), intentou-se aqui um esquema distintivo das 3 grandes fases do pentecostalismo brasileiro com suas respectivas denominações, origens, igrejas, distinções conceituais, operacionais e atitudinais em relação as Escrituras e a sociedade (quadro 1). É certo que no presente trabalho não faz parte do escopo temático se aprofundar sobre o tema. Todavia, o surgimento e expansão das igrejas componentes do "Pentecostalismo Clássico" ao "Neopentecostalismo", passando pelo "Deuteropentecostalismo", contribuíram significativamente para o enfraquecimento institucional daquelas entidades religiosas protestantes instaladas no Brasil ainda no século XIX (Luterana, Metodista, Presbiteriana, Batista), estas entendidas como resultado das correntes migratórias que afluíram para o país no período histórico mencionado.

Destarte, verifica-se que o grande ímpeto pentecostal assistido hodiernamente no Brasil com líderes religiosos participando ativamente muitas vezes como protagonistas da vida política e partidária nacional e com o acréscimo exponencial de fiéis/seguidores com base no impulso midiático que a apropriação de meios de comunicação de massa oferecem (concessões governamentais de rádio e TV), teve sua gênese no início do século XX no país. 
Quadro 1: As "três ondas" do Pentecostalismo no Brasil

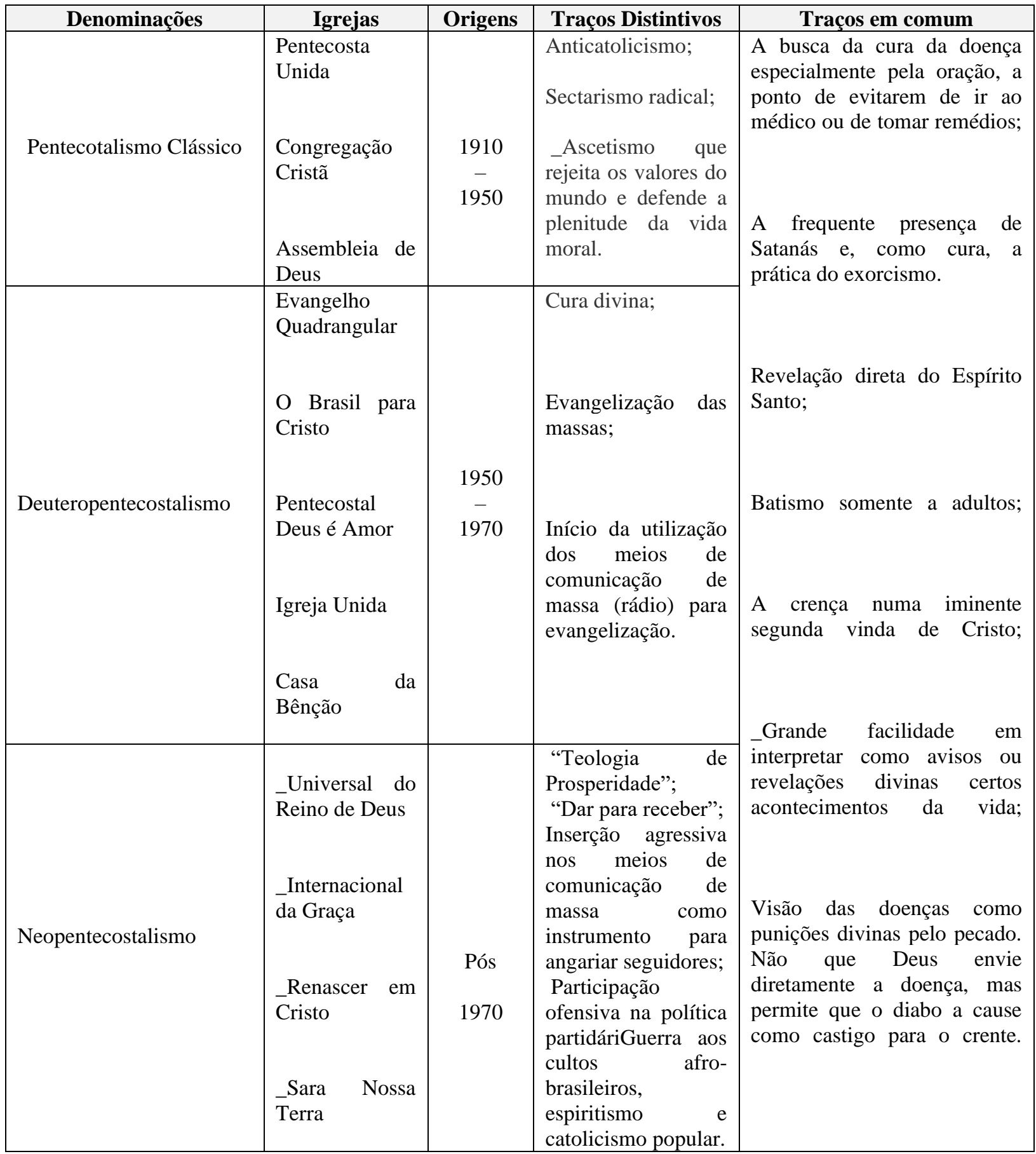

Fonte: O autor, 2020, a partir de MARIANO, 2005; FRESTON, 2006; e CIPRIANI, 2020.

Assim, a primeira fase corresponde ao "Pentecostalismo clássico" (1910-1950), que se baseia na crença do poder do Espírito Santo na vida do crente após o Batismo do Espírito 
Santo, através dos dons do Espírito Santo, começando com o dom de línguas (glossolalia) (FRESTON, 2006).

Já a segunda grande fase corresponde ao "Deuteropentecostalismo" (1950-1970). Enfatiza-se a cura divina e profecias, embora valorize o falar em línguas, distingue-se do Pentecostalismo Clássico pelo seu menor foco nesse carisma. Quanto à ética e costumes, há uma polarização, e tornou-se mais rígido o caso da Igreja Pentecostal Deus é Amor, ou mais liberal como na Igreja do Evangelho Quadrangular. Percebe-se, nesta Igreja, pouca característica sectária e ascética, por isso, há uma tendência de se investir em "atividades extra-igreja” (MARIANO, 2005).

Ao contrário do "Pentecostalismo Clássico" em que as abordagens do inferno e do pecado sejam os temas mais nevrálgicos dos discursos em pregação, o "Deuteropentecostalismo", segundo Freston foca:

em favor do apelo às necessidades sentidas de cura física e psicológica, sinal de adaptação às sensibilidades da sociedade de consumo e às exigências do mercado religioso; e em que os tabus comportamentais são abrandados, pois já deixaram de ser funcionais para amplos setores urbanos (FRESTON, 1996, p. 113).

Já no que concerne ao "Neopentecostalismo", que ganha destaque no Brasil a partir do último quarto do século XX e se aprofunda nas décadas de 1980 e 1990 com as aquisições de grandes e influentes meios de comunicação de massa via concessões governamentais, o pensamento organizacional/empresarial das igrejas desta terceira onda indica que a religião e mídia tem de pertencer aos mesmos proprietários, pois o próprio ato da comunicação e midiatização são as mediações centrais para a consolidação do poder religioso e político de tais igrejas como Universal do Reino de Deus (IURD), Internacional da Graça ou Renascer em Cristo.

A base teológica dos neopentecostais é a "Teologia da Prosperidade". Segundo Mariano (2005, p. 160) o neopentecostalismo basicamente demoniza a pobreza e a enfermidade e que a única maneira de exorcizá-los é praticar o "dar para receber". Conjugadamente, a valorização da prosperidade material mediante contribuição financeira, a ausência do legalismo em matéria comportamental com a liberalização dos tradicionais usos e costumes de santidade pentecostal aparecem como as novas "roupagens" do neopentecostalismo em relação ao "Pentecostalismo Clássico".

As Igrejas Neopentecostais realizaram as mais significativas flexibilizações à sociedade abandonando vários traços sectários, hábitos ascéticos e o velho estereótipo pelo 
qual os "crentes" eram reconhecidos e, implacavelmente, estigmatizados, abolindo certas marcas distintivas e tradicionais de sua religião, propondo novos ritos, crenças e práticas, dando ares mais brandos aos costumes e comportamentos como em relação às vestimentas. $\mathrm{O}$ prefixo "neo" é utilizado para marcar sua recente formação, bem como seu caráter de "novidade" dentro do protestantismo, mais especificamente do pentecostalismo (SÉLMAN, 2019).

Não obstante, o traço mais marcante do Neopentecostalismo é sua "midiatização" exacerbada através da forma com que se usa os meios de comunicação para a evangelização no Brasil, mas, também, em outras partes do mundo. Insere-se de forma peculiar, na linguagem das mídias - tv, rádio, gravadora, jornal, internet, arregimentando um número cada vez maior de fiéis.

Posto isto, a seção que se segue, alicerçado no exame quantitativo e qualitativo das leis aprovadas em plenário, abordará precisamente os mecanismos de influência, controle e domínio de uma representação parlamentar voltada aos interesses de grupos religiosos de igrejas inseridas nessas 3 fases do Pentecostalismo brasileiro.

\section{O ATIVISMO PARLAMENTAR PENTECOSTAL NA REPRODUÇÃO LEGISLATIVA DA BAIXADA FLUMINENSE/RJ}

Em pesquisa realizada pelo demógrafo José Eustáquio Alves no âmbito da Escola Nacional de Ciências Estatísticas do IBGE a religião evangélica cresce cerca de $1 \%$ ao ano, enquanto o catolicismo perde 1,2\% no mesmo período. Conforme demonstra o gráfico 1, os evangélicos crescendo num ritmo geométrico e mantida a tendência de queda do catolicismo, a partir de 2030 indica um cenário religioso no Brasil que apontará pela primeira vez na história do "maior país católico do mundo" 8 em termos de fiéis, os evangélicos serem maioria no país.

\footnotetext{
${ }^{8}$ De acordo com o site Aleteia. Consulta em 23/09/2020. Disponível em: https://pt.aleteia.org/2019/01/21/os-10maiores-paises-catolicos-do-mundo/
} 
Gráfico 1: Avanço evangélico no Brasil (em percentual do total de fiéis no país)

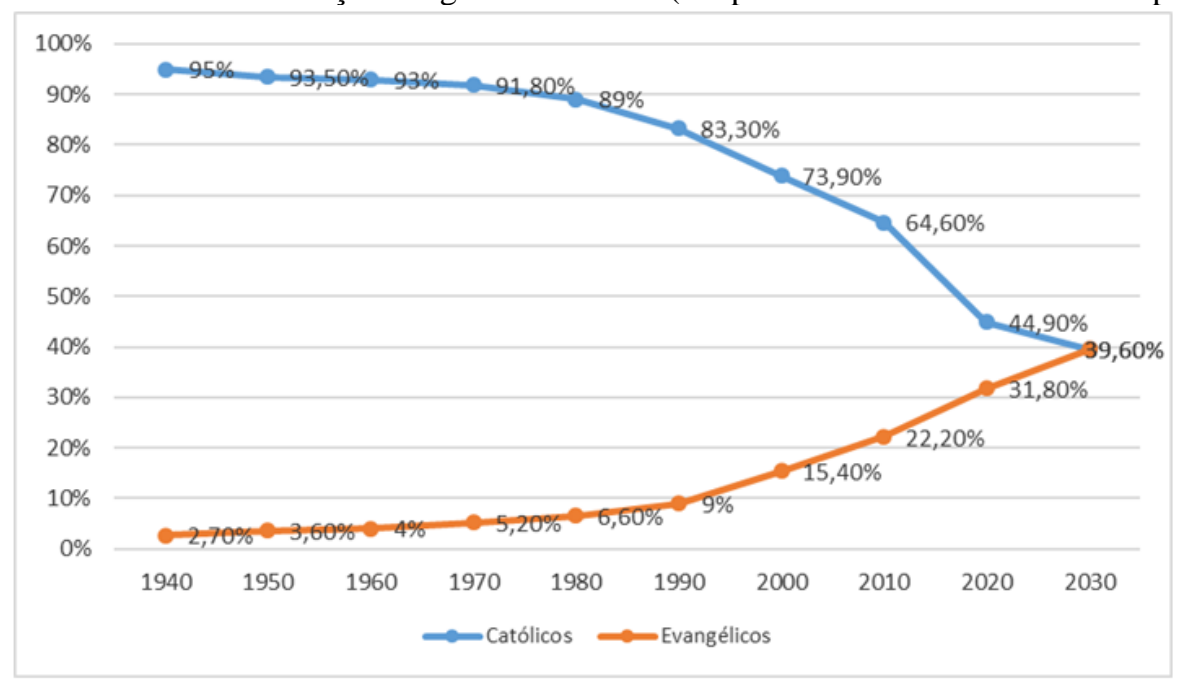

Fonte: IBGE. Organizado e elaborado pelo autor, 2020.

Já em matéria realizada pelo jornalista Reinaldo Azevedo para o seu blog${ }^{9}$, assevera que o pentecostalismo no Brasil já contaria hoje com cerca de 24 milhões de adeptos. Embora bem minoritários quando se consideram os cerca de 88 milhões de católicos, isso já torna o Brasil, maior país católico do planeta, também o maior neopentecostal.

No escopo territorial em pauta, a ordem de grandeza da influência das igrejas pentecostais reside no fato de que das 13 unidades municipais que perfazem o conjunto territorial da Baixada Fluminense/RJ, 9 municípios apresentam mais fiéis da matriz evangélica (gráfico 2), quando comparados aos católicos, ainda maioria no Brasil conforme destacado precedentemente. Quando a análise se direciona para a uma média global de toda região de estudo aqui privilegiada, as religiões evangélicas configuram-se maioria (gráfico 3). Torna-se importante destacar nesse momento para fins metodológicos que a consecução dos dados baseou-se, conforme demonstrado, no Instituto Brasileiro de Geografia e Estatística (IBGE), e este só tabulou os dados referentes as 3 religiões aqui apresentadas, não incluindo o vasto horizonte que perfaz o sincretismo religioso brasileiro.

\footnotetext{
9 Pesquisa realizada em 31 de julho de 2020 pelo World Christian Database, base de dados elaborada pelo Seminário de Teologia Gordon-Conwell dos EUA. Consulta em 16/10/2021. Disponível em: https://veja.abril.com.br/blog/reinaldo/brasil-o-maior-pais-catolico-do-mundo-ja-e-o-maior-pais-pentecostal-dequem-e-a-culpa/.
} 
Gráfico 2 - População residente por religião nos municípios da Baixada Fluminense/RJ

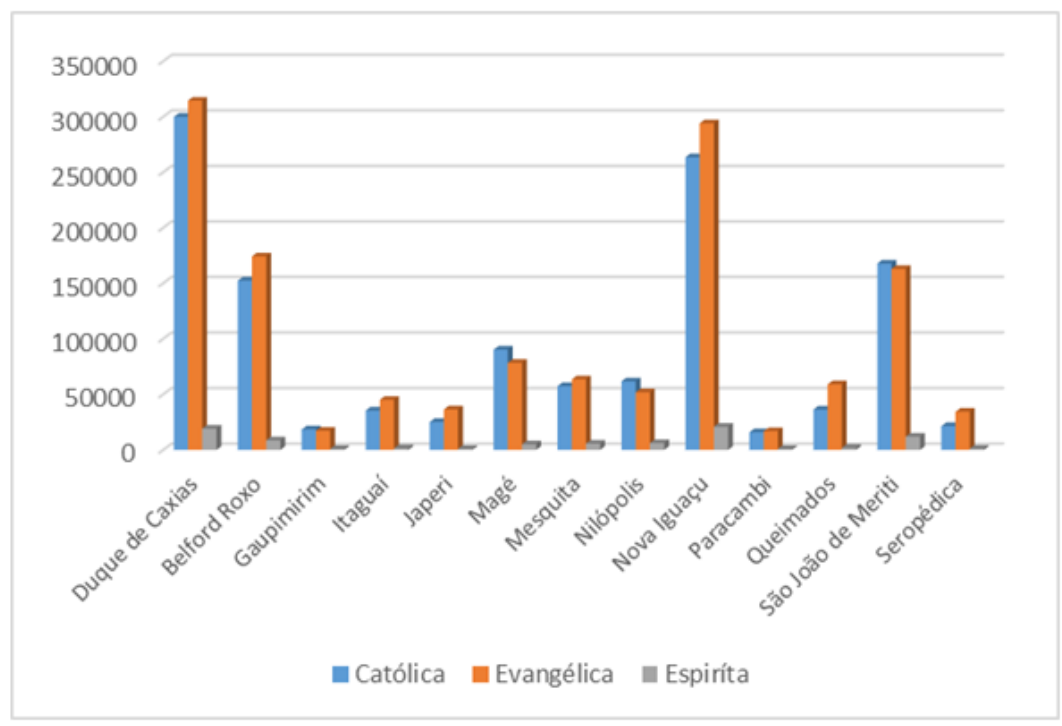

Fonte: IBGE. Organizado e elaborado pelo autor, 2020.

Gráfico 3: População residente por religião na Baixada Fluminense/RJ (\%)

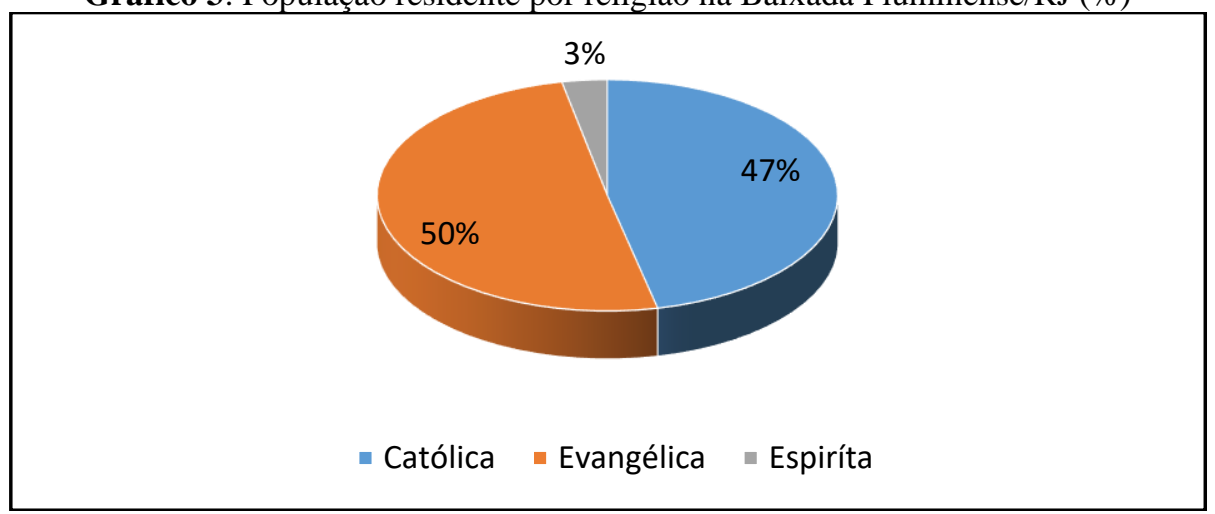

Fonte: IBGE. Organizado e elaborado pelo autor, 2020.

Desse modo, é ambicionado aqui a proposta de investigação sobre como o segmento pentecostal se insere na política partidária e nas formulações estruturantes da representação parlamentar nos municípios da Baixada Fluminense/RJ. Destarte, o eixo central de pesquisa é: a igreja evangélica como um dos elementos constitutivos de poder político e a representação parlamentar baseado no ativismo pentecostal atestado nas leis aprovadas em plenário como mola propulsora desse processo.

Tendo como exemplo o segundo maior município da Baixada Fluminense/RJ em termos demográficos, Nova Iguaçu ${ }^{10}$, é ratificado na tabela 2 que na legislatura 2017-20 foram 23 leis aprovadas em plenário, 8,6 \% do total, que fazem menção direta à religião em expedientes legislativos que estruturam e edificam a influência pentecostal no município. Se a

\footnotetext{
${ }^{10}$ De acordo com as estimativas de população do IBGE, Nova Iguaçu conta com 796.257 habitantes, só perdendo na Baixa Fluminense/RJ em termos demográficos para Duque de Caxias com 855. 046 habitantes.
} 
esse fato somar-se a representação parlamentar transformada em leis que envolvem a concessão do título de Utilidade Pública, 36 documentos, 13,4 \% do total, e que tais concessões direcionam-se diretamente as entidades pentecostais localizadas no município em questão, admite-se que são cerca de um quinto de leis que contemplam a hipótese levantada nas presentes linhas: que o pentecostalismo é, nos tempos hodiernos, um ente protagonista na luta pelo controle político.

Tabela 2 - Distribuição das leis por temas em Nova Iguaçu - Legislatura 2017/2020

\begin{tabular}{|c|c|c|c|c|c|}
\hline Temas & Categorias & \multicolumn{2}{|c|}{ Recorrências } & $\%$ & \% Total \\
\hline \multirow{4}{*}{$\begin{array}{l}\text { Burocrático- } \\
\text { administrativo }\end{array}$} & Administração & \multirow[b]{4}{*}{138} & 46 & $17.2 \%$ & \multirow{4}{*}{$51,6 \%$} \\
\hline & Denominação de logradouro público & & 52 & $19.4 \%$ & \\
\hline & Implementação tributária & & 4 & $1.5 \%$ & \\
\hline & Concessão de título de utilidade pública & & 36 & $13.4 \%$ & \\
\hline \multirow{5}{*}{ Cidadania } & Direitos da mulher & \multirow{5}{*}{28} & 6 & $2.2 \%$ & \multirow{5}{*}{$10,4 \%$} \\
\hline & $\begin{array}{l}\text { Direitos a pessoas } \\
\text { com deficiência }\end{array}$ & & 5 & $1.8 \%$ & \\
\hline & Direitos das crianças & & 4 & $1.5 \%$ & \\
\hline & Direitos dos Idosos & & 2 & $0.7 \%$ & \\
\hline & Ações afirmativas raciais & & 11 & $4.1 \%$ & \\
\hline \multirow{3}{*}{ Saúde } & Saúde & \multirow{3}{*}{4} & 2 & $0.7 \%$ & \multirow{3}{*}{$1,4 \%$} \\
\hline & Combate à pandemia & & 2 & $0.7 \%$ & \\
\hline & Defesa civil & & 0 & $0 \%$ & \\
\hline \multirow[t]{2}{*}{ Economia } & Fazenda/ Planejamento & \multirow[t]{2}{*}{15} & 15 & $5.6 \%$ & \multirow[t]{2}{*}{$5,6 \%$} \\
\hline & Emprego e renda & & 0 & $0 \%$ & \\
\hline \multirow[t]{2}{*}{ Meio ambiente } & Sustentabilidade/conservação & \multirow[t]{2}{*}{6} & 5 & $1.8 \%$ & \multirow[t]{2}{*}{$2,1 \%$} \\
\hline & Direitos dos animais & & 1 & $0.3 \%$ & \\
\hline \multirow[t]{2}{*}{ Educação } & Educação & \multirow[t]{2}{*}{17} & 9 & $3.3 \%$ & \multirow[t]{2}{*}{$6,2 \%$} \\
\hline & Esportes e lazer & & 8 & $2.9 \%$ & \\
\hline \multirow[t]{2}{*}{ Urbanismo } & Habitação & \multirow[t]{2}{*}{15} & 2 & $0.7 \%$ & \multirow[t]{2}{*}{$5,5 \%$} \\
\hline & Ordenamento urbano & & 13 & $4.8 \%$ & \\
\hline \multirow[t]{2}{*}{ Transportes } & Transportes & \multirow[t]{2}{*}{4} & 4 & $1.4 \%$ & \multirow[t]{2}{*}{$1,4 \%$} \\
\hline & Serviços públicos & & 0 & $0 \%$ & \\
\hline \multirow[t]{2}{*}{ Turismo } & Turismo & \multirow[t]{2}{*}{12} & 1 & $0.3 \%$ & \multirow[t]{2}{*}{$4,4 \%$} \\
\hline & Cultura & & 11 & $4.1 \%$ & \\
\hline Segurança & Segurança & 4 & 4 & $1.4 \%$ & $1,4 \%$ \\
\hline Sociedade & Religião & 23 & 23 & $8.6 \%$ & $8,6 \%$ \\
\hline Infraestrutura & Obras & 0 & 0 & $0 \%$ & $0 \%$ \\
\hline \multicolumn{2}{|l|}{ Total } & \multicolumn{2}{|c|}{267} & $100 \%$ & $100 \%$ \\
\hline
\end{tabular}

Fonte: Arquivo da Câmara Municipal de Nova Iguaçu. Organizado pelo autor, 2020. 
É imperioso ressaltar a importância e o nexo entre à representação parlamentar concebida no grande número de leis aprovadas em plenário que versa sobre religião e as leis que visam a concessão de título de Utilidade Pública. As figuras 1, 4 e 5, expressão do parlamento iguaçuano, são apenas alguns exemplos em que se pode apreciar a representação parlamentar municipal favorecendo igrejas evangélicas/pentecostais com a outorga dos títulos de Utilidade Pública pelo Parlamento Municipal, reconhecendo nessas entidades função social e que, por isso, devem ser agraciadas com isenção e/ou redução de impostos que competem à esfera municipal como o Imposto Sobre Serviços (ISS), o Imposto Predial e Territorial Urbano (IPTU) e o Imposto de Transmissão de Bens Imóveis (ITBI), além de outras vantagens institucionais tais como facilidades na obtenção de alvarás de funcionamento, além de doação de terrenos para edificação dos templos religiosos.

Figura 1 - LEI No 4.690 DE 06 DE DEZEMBRO DE 2017 - Nova Iguaçu

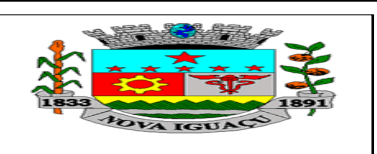

Estado do Rio de Janeiro Prefeitura da Cidade de Nova Iguaçu

Reconhece de Utilidade Pública a Igreja Assembleia Pentecostal Encontro com Deus.

Autor: Vereador Carlos Alberto C. Chambarelli - Carlão Chambarelli A CÂMARA MUNICIPAL DA CIDADE DE NOVA IGUAÇU, POR SEUS REPRESENTANTES LEGAIS, DECRETA E EU SANCIONO A SEGUINTE LEl:

Art. 1․ Fica reconhecida de utilidade pública a IGREJA ASSEMBLEIA PENTECOSTAL

ENCONTRO COM DEUS, fundada em 12 de fevereiro de 2012, inscrita no CNPJ sob o $\mathrm{n}$. 22.075.608/0001-18, com sua constituição e fundação devidamente registrada no Cartório do $3^{\circ}$ ofício de Justiça de Nova Iguaçu, protocolo sob o no 4322 o n. de ordem 18647, com sede na rua Adail, 39, Prata, Nova Iguaçu/RJ.

Art. $2^{\circ}$ - Reconhecida e declarada de utilidade pública a IGREJA ASSEMBLEIA PENTECOSTAL ENCONTRO COM DEUS passa a gozar de todas as prerrogativas que a lei confere as entidades detentoras deste título.

Art. $3^{\circ}$ - Esta Lei entrará em vigor na data de sua publicação, revogando-se as disposições em contrário. Nova Iguaçu, 06 de dezembro de 2017. ROGÉRIO MARTINS LISBOA - PREFEITO

Fonte: Arquivo de Documentação da Câmara Municipal de Nova Iguaçu. Elaborado pelo autor, 2020.

Figura 2 - LEI No 4.804 DE 03 DE DEZEMBRO DE 2018 - Nova Iguaçu

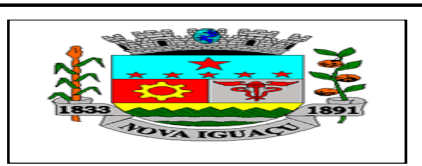

Estado do Rio de Janeiro Prefeitura da Cidade de Nova Iguaçu

Institui e inclui no Calendário Oficial da Cidade de Nova Iguaçu o Dia Municipal do Pastor Evangélico, e dá providências. Autor: Vereador Rogério Teixeira Junior - JUNINHO DO PNEU

A CÂMARA MUNICIPAL DA CIDADE DE NOVA IGUAÇU, POR SEUS REPRESENTANTES LEGAIS, DECRETA E E SANCIONO A SEGUINTE LEI:

Art. $1^{\circ}$ Passa a fazer parte do Calendário Oficial da Cidade o Dia Municipal do Pastor Evangélico, que será celebrado no segundo domingo de junho de cada ano, na Cidade de Nova Iguaçu.

Art. $2^{\circ} \mathrm{O}$ chefe do Poder Executivo regulamentará esta Lei, no que couber, no prazo de 60 (sessenta) dias, contados da data de sua publicação.

Art. $3^{\circ}$ Esta Lei entra em vigor na data de sua publicação. Nova Iguaçu, 03 de dezembro de 2018. 
Fonte: Arquivo de Documentação da Câmara Municipal de Nova Iguaçu. Elaborado pelo autor, 2020.

Figura 3 - LEI No 4.686 DE 06 DE DEZEMBRO DE 2017 - Nova Iguaçu

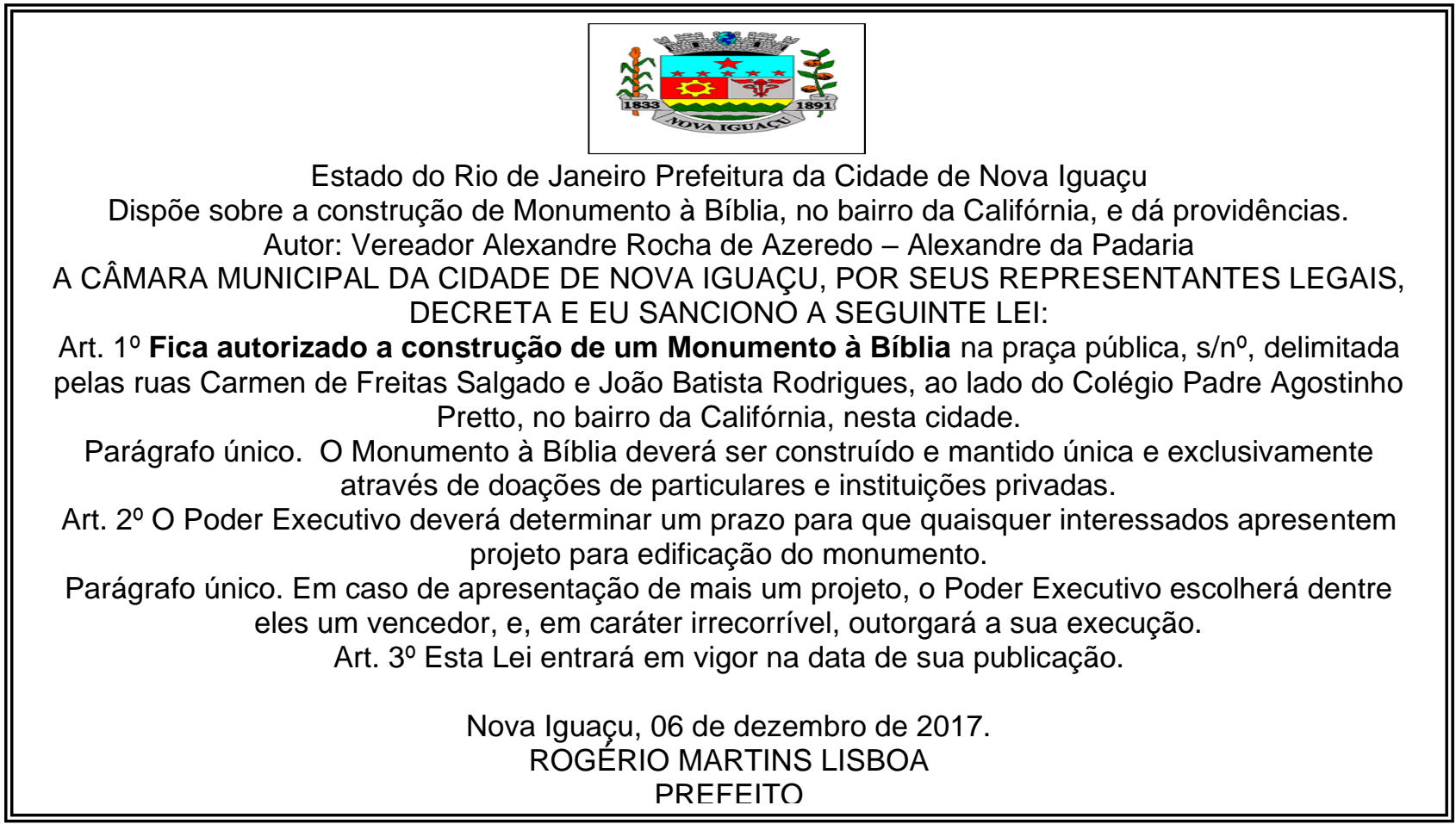

Fonte: Arquivo de Documentação da Câmara Municipal de Nova Iguaçu. Elaborado pelo autor, 2020.

Figura 4 - LEI Nº 4.651 DE 10 DE MARÇO DE 2017 - Nova Iguaçu

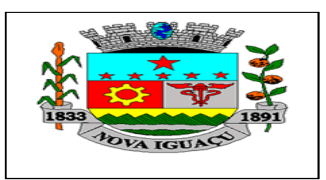

Estado do Rio de Janeiro Prefeitura da Cidade de Nova Iguaçu

Reconhece de Utilidade Pública a Associação da Igreja Metodista - 1aㅡ Região Eclesiástica.

Autor: Carlão Chambarelli A CÂMARA MUNICIPAL DE NOVA IGUAÇU, POR SEUS

REPRESENTANTES LEGAIS, DECRETA E EU SANCIONO A SEGUINTE LEI:

Art. $1^{\circ}$ Fica reconhecida de Utilidade Pública a Associação da Igreja Metodista - $1^{\text {a }}$ Região

Eclesiástica, inscrita no CNPJ sob o n‥ 03.502.814/0085-20, devida-mente registrada no Registro

Civil das Pessoas Jurídicas da Comarca da Capital do Rio de Janeiro, averbação matrícula protocolo

№. 3296, datado de 29/11/2007, com subsede na Rua Matilde Queiroz, 45, Comendador Soares, Nova Iguaçu/RJ.

Art. $2^{\circ}$ - Reconhecida e declarada de Utilidade Pública, a Associação da Igreja Metodista - $1^{\text {a }}$ Região Eclesiástica, passa a gozar de todas as prerrogativas que a Lei confere às entidades detentoras deste título.

Art. 3ํ- Esta Lei entrará em vigor na data de sua publicação, revogando-se as disposições em contrário.

Prefeitura da Cidade de Nova Iguaçu, 10 de março de 2017.

ROGÉRIO MARTINS LISBOA

Prefeito

Fonte: Arquivo de Documentação da Câmara Municipal de Nova Iguaçu. Elaborado pelo autor, 2020. 
Figura 5 - LEI No 4.892 DE 22 DE ABRIL DE 2020 - Nova Iguaçu

\begin{tabular}{|c}
\hline Reconhece de Utilidade Pública a Igreja do Nazareno Central de Nova Iguaçu. \\
Autor: Vereador Carlos Alberto Curi Chambarelli - CARLÃO CHAMBARELLI \\
EU SANCIONO A SEGUINTE LEI: \\
A CÂMARA MUNICIPAL DE NOVA IGUACU, POR SEUS REPRESENTANTES LEGAIS, DECRETA E \\
Art. 10 Fica reconhecida de Utilidade Pública a Igreja do Nazareno Central de Nova Iguaçu, \\
inscrita no CNPJ sob o número 17.640.641/0001-03, com sua constituição devidamente registrada no \\
Cartório do 80 Ofício de Nova Iguaçu, Registro Civil das Pessoas Jurídicas sob o no de ordem 13904, \\
no livro A-24, com endereço na Av. Governador Portela, 525, Centro, Nova Iguaçu/RJ. \\
Art. 20 Reconhecida e declarada de Utilidade Pública, a lgreja do Nazareno Central de Nova \\
Iguaçu passa a gozar de todas as prerrogativas que a lei confere às entidades detentoras deste \\
título. \\
Art. ${ }^{\circ}$ Esta Lei entra em vigor na data de sua publicação. \\
ROGÉRIO MARTINS LISBOA - Prefeito \\
\hline
\end{tabular}

Fonte: Arquivo de Documentação da Câmara Municipal de Nova Iguaçu. Elaborado pelo autor, 2020.

Já as figuras 2 e 3, versam dentro do mesmo parlamento de Nova Iguaçu, respectivamente, sobre a instituição do Dia Municipal do Pastor Evangélico no município e a construção de um monumento à Bíblia. Inseridos na mesma perspectiva temática, os dois documentos legislativos só vêm corroborar um explícito cenário parlamentar em que o ativismo pentecostal estrutura e organiza a fundamentação religiosa em que se baseia expressiva parcela da representação política observada nas leis aprovadas em plenário.

À guisa de constatação do fato das correntes pentecostais serem também em outros municípios da Baixada Fluminense/RJ um elemento de injunção nas suas relações com a política com desdobramentos na sociedade e no espaço geográfico em tela, alguns exemplos são evidenciados nas figuras 6, 7 e 8 atestando, deste modo, como essa nova força de poder pentecostal busca tornar-se um dos elementos hegemônicos do poder político municipal. A figura 6 faz menção no município de Queimados a um ordenamento em que prevê a prerrogativa em que as entidades religiosas passam a dispor de isenção do Imposto Predial e Territorial Urbano (IPTU); a figura 7 no município de Itaguaí refere-se a um expediente legislativo em que nota-se a influência evangélica no seu Parlamento Municipal no sentido de se instituir legalmente uma data comemorativa ao "Pastor evangélico"; além da lei sancionada no município de Paracambi demonstrada na figura 8 que reconhece de Utilidade Pública a Igreja Evangélica Assembleia de Deus Ministério Palavra de Paz. 


. Autor: Vereador Elerson Leandro Alves.
“DISPÕE SOBRE A FORMA DE CONCESSÃO DA IMUNIDADE DO IMPOSTO PREDIAL E
TERRITORIAL URBANO REFERENTE AOS TEMPLOS RELIGIOSOS SITUADOS NO MUNICÍPIO
DE QUEIMADOS E DÁ OUTRAS PROVIDENCIAS.”
Faço saber que a Câmara Municipal de Queimados APROVOU e eu SANCIONO a seguinte lei:
Art. 10 - As instituições religiosas situadas no Município de Queimados deverão requerer a
imunidade do Imposto Predial e Territorial Urbano - IPTU, conforme previsto no artigo 150, VI, b,
da Constituição Federal, através de requerimento dirigido à Secretaria Municipal de Fazenda e
Planejamento. Parágrafo único - O requerimento deverá ser autuado no Protocolo Geral e conterá, no
mínimo, os seguintes documentos: I. Escritura e Registro do Imóvel, em nome da Instituição; II. Ata de
eleição da Diretoria ou documento equivalente; III. Documentação do responsável legal; IV. CNPJ; V.
Inscrição Municipal.
Art. ${ }^{\circ}$ - Deferido o pedido pela autoridade competente, fica determinado a sua reiteração
automática anual pelo período de 20 (vinte) anos. Parágrafo único - A Prefeitura Municipal de
Queimados poderá, a qualquer tempo, solicitar às entidades religiosas cópias atualizadas dos
documentos mencionados no parágrafo único do artigo 1o.
Art. 3o - O Poder Executivo regulamentará a presente Lei no prazo de 60 (sessenta) dias. Art. 4ำ - Esta
Lei entrará em vigor na data de sua publicação, revogando as disposições em contrário.
CARLOS DE FRANÇA VILELA
P R E F E I T O

Fonte: Arquivo de Documentação da Câmara Municipal de Queimados. Elaborado pelo autor, 2020.

Figura 7 - LEI N 3.728 DE 02 DE ABRIL DE 2019 - Itaguaí

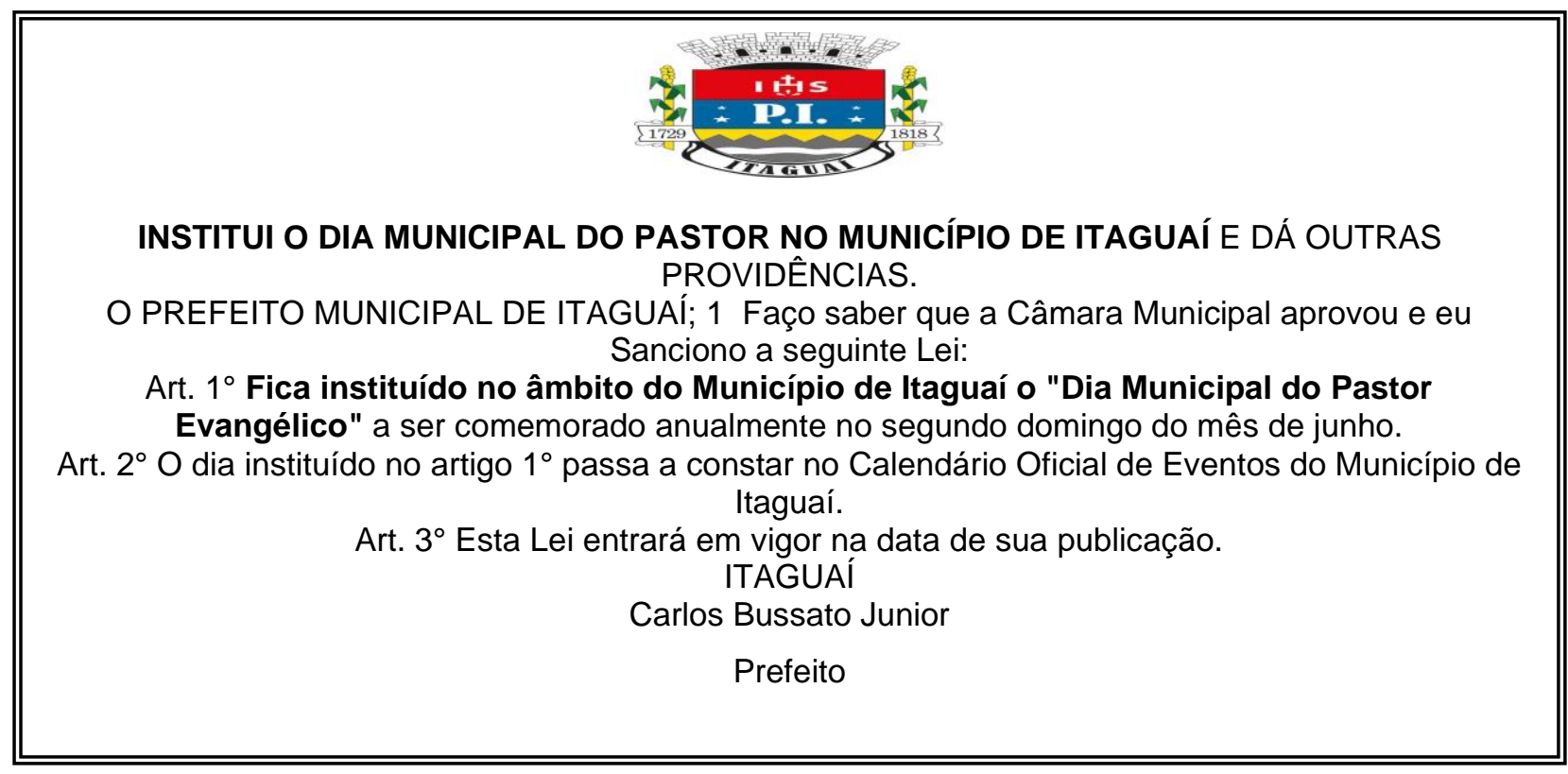

Fonte: Arquivo de Documentação da Câmara Municipal de Itaguaí. Elaborado pelo autor, 2020. 
Figura 8 - LEI MUNICIPAL N 1.320. DE 25 DE JUNHO DE 2018 - Paracambi

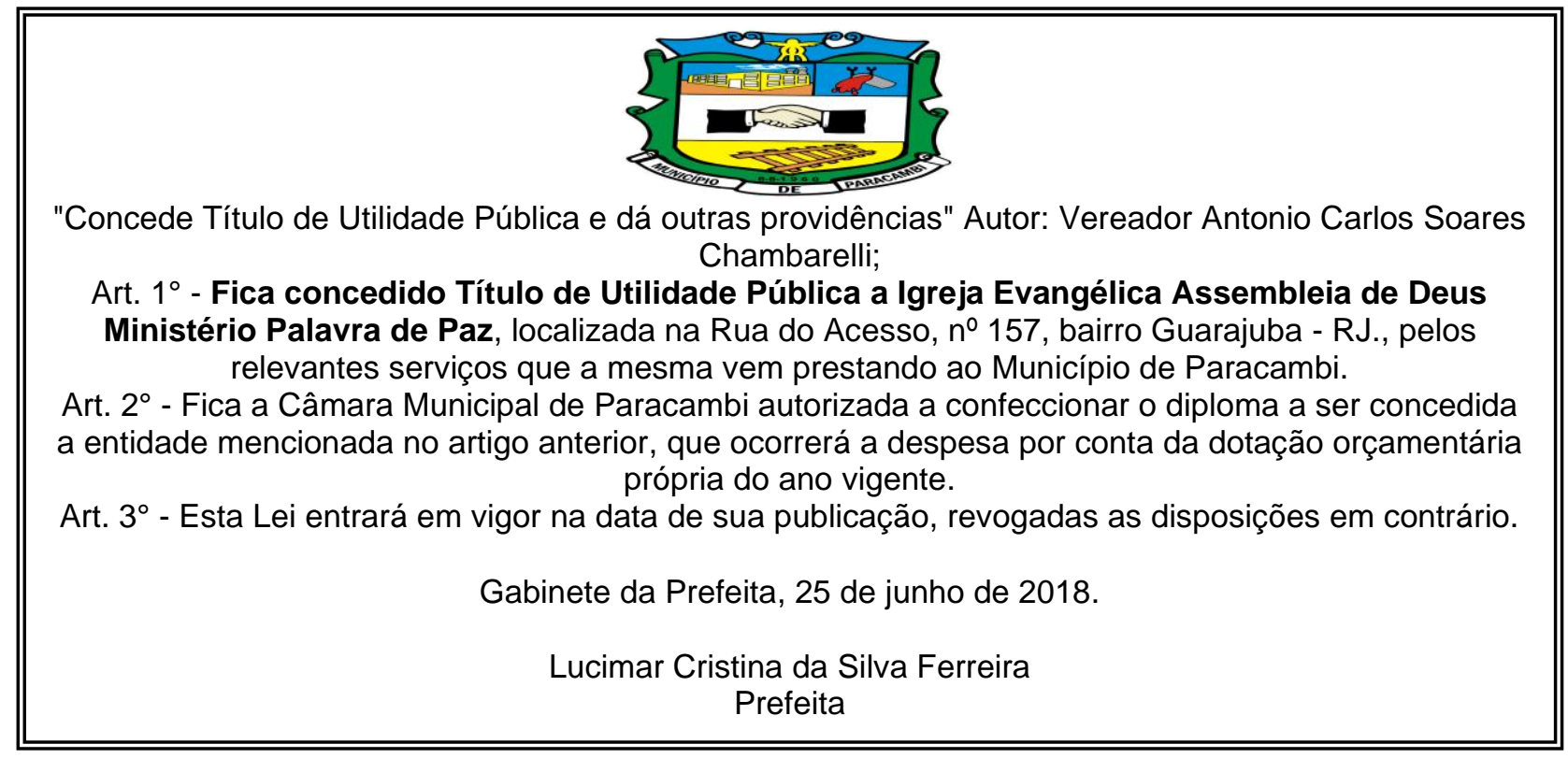

Fonte: Arquivo de Documentação da Câmara Municipal de Queimados. Elaborado pelo autor, 2020.

Com a observância metódica dos ordenamentos regulatórios, as leis aprovadas em plenário, permite-se inferir também aqui o papel da influência evangélica/pentecostal uma agenda moralizante dos costumes, a denominada "pauta moral". Para corroborar a expectativa de pesquisa trazida à luz neste artigo, Ramos e Zacarias (2017) asseveram que:

\begin{abstract}
A luta pela pauta moral intensificou nos evangélicos a consciência, ou a inclinação, para a construção de um Estado cristão e para uma possível hegemonia amparada pelo crescimento sistêmico e exponencial de sua Igreja no país. Não poucos líderes começaram a vislumbrar a possiblidade, e a necessidade desse Estado evangélico para a imposição de uma agenda conservadora sobretudo na esfera dos costumes. (RAMOS e ZACARIAS, 2017).
\end{abstract}

Tratam-se de leis que versam não somente ao emprego e aproveitamento de vantagens institucionais conforme mencionado alhures como isenções fiscais municipais aferidas nas concessões de Utilidade Pública, mas similarmente como endossa os referidos autores, uma representação parlamentar compromissada com uma agenda conservadora nos costumes.

A consonância do referencial teórico-conceitual dos autores acima e os pilares da pesquisa aqui propostos, encontra exatamente nesta perspectiva do binômio religião-política seu ponto nevrálgico: o quão de domínio, controle e influência a representação parlamentar evangélica/pentecostal tem nos Parlamentos Municipais da Baixada Fluminense/RJ na criação de leis que criem "uma consciência evangélica" sobre os costumes e a moral na sociedade e os símbolos (objetos geográficos) construídos no território?

Além dos já citados ordenamentos regulatórios mencionados anteriormente de autoria parlamentar evangélica/pentecostal com grande capilaridade na sociedade e território da 
Baixada Fluminense/RJ, outros exemplos de leis podem ser evidenciados, tais como: a criação de um "Monumento à Bíblia" em Nova Iguaçu verificado na figura 3; a instituição do "Dia Municipal do Pastor Evangélico" em Itaguaí realçado na figura 7; ou aqueles que se mostram como entraves aos direitos humanos, causas feministas, identidade de gênero, liberalização do aborto e minorias LGBT, ou na comprovada ausência ou insuficiência destas quando confrontadas com a quantidade de leis aprovadas referentes ao funcionamento da "máquina administrativa" altamente burocratizada e de viés extremamente economicista (tabela 2).

Torna-se imperioso destacar que a formação e consolidação de frentes parlamentares notadamente evangélica e mais precisamente pentecostal é um processo em curso no Brasil com grande capilaridade tanto em outros parlamentos municipais como em outras instâncias legislativas pertencentes a distintas escalas da administração (Assembleias Estaduais, Câmara Federal e Senado).

É pertencente a esta conjuntura que a contribuição teórico-conceitual de Mariano (2015) em sua profunda averiguação sobre as origens e expansão do pentecostalismo no Brasil torna-se imperiosa. O aludido autor destaca, desde a promessa da cura divina, passando pela sustentação religiosa de uma "pauta moral" sobre os costumes, até a apropriação sistemática de importantes meios de comunicação como concessões públicas e/ou aquisições de rádio e TV, comprova que o mais fulgurante aspecto condizente ao pentecostalismo no arranjo social contemporâneo no Brasil é, sem dúvida, as inserções na política partidária com sólidas representações parlamentares. O referido autor sustenta que,

\begin{abstract}
o que nos chama a atenção é que, se outrora havia ainda um passo tímido no sentido da participação política, ou até mesmo um comodismo por parte dos adeptos ao pentecostalismo clássico, hoje, com a explosão do neopentecostalismo, este quadro mudou. Candidatos são lançados e apoiados por grande parte das comunidades evangélicas. Nas palavras de Mariano, a velha máxima "crente não se mete em política" deu lugar ao slogan "irmão vota em irmão". (MARIANO, 2015, p. 354)
\end{abstract}

Isto posto, a abordagem da expansão do pentecostalismo no Brasil reside no questionamento, no recorte territorial da Baixada Fluminense/RJ, da visível aliança entre religião e poder político. Essa associação com o intuito de reivindicar uma representação religiosa, propriamente pentecostal, no âmbito da representação legislativa, objetiva a criação e sustentação de uma maioria para garantir e fortalecer sua agenda.

Por conseguinte, a apreensão da gênese e evolução/expansão da religião evangélica no Brasil visa subsidiar como as transformações no seio deste segmento no país (criação e dissidências das igrejas) desencadeou o pentecostalismo e o seu elo contemporâneo com a 
política, seu crescimento exponencial do número de representantes na atividade parlamentar, culminando até na inquestionável contribuição eleitoral que as igrejas pentecostais deram à eleição do atual presidente do Brasil, Jair Messias Bolsonaro em 2018.

Ademais, o imbricamento do pentecostalismo com a política na escala da Baixada Fluminense/RJ mediante a apreciação dos ordenamentos regulatórios derivados do trabalho parlamentar, parece encontrar inquestionáveis consonâncias em outras escalas, mormente a federal. Filho (2019) em entrevista ao site "Portal da Esquerda", sentencia que,

boa parte do país e muitos observadores estrangeiros permanecem em estado de espanto diante da escolha de 57,7 milhões de brasileiros. Entre os muitos fatores que explicam a eleição de Bolsonaro, talvez um dos menos explorados seja o papel do eleitor evangélico que, segundo o diretor do Instituto Vox Populi, Marcos Coimbra, acabou decidindo as eleições - especialmente as mulheres evangélicas. Como foi possível para boa parte desta fatia do povo brasileiro que professa a fé em Jesus Cristo, perseguido e torturado exatamente por suas posições políticas e religiosas segundo os Evangelhos, apoiar o ex-capitão entusiasta da ditadura militar que inclusive tornou-se o primeiro presidente eleito a determinar que o aniversário do golpe militar fosse comemorado oficialmente? (FILHO, 20019).

\section{CONSIDERAÇÕES FINAIS}

O trabalho em tela buscou realçar o debate da representação parlamentar e seus nexos com um notável domínio evangélico na estruturação de atuação política na Baixada Fluminense/RJ. Dentro de um contexto de um marcante conservadorismo político/religioso notadamente evangélico/pentecostal que atravessa o Brasil atual no governo de Jair Bolsonaro, intentou-se mostrar como um ativismo parlamentar pentecostal passou a ser um dos elementos constitutivos do poder político e a representação parlamentar baseada nas leis aprovadas em plenário como fundamento primordial desse processo, tendo os desdobramentos desse poder pentecostal e neopentecostal na organização e estruturação da sociedade e no território da região em pauta.

A esperança do presente trabalho é que tenha ficado claro como a representação parlamentar é influenciada pela força religiosa evangélica e que também seja nítida a percepção de como numa região como a Baixada Fluminense/RJ de múltiplas carências sociais e econômicas, cenário histórico do familismo e do clientelismo, o componente pentecostal como força parlamentar seja capaz de agregar novas forças políticas e/ou reordenar antigos grupos de interesses político e religioso dentro da estrutura de representação política.

Essa imbricada rede de relações entre a representação parlamentar e um ativismo pentecostal na formulação de leis que assegurem desde prerrogativas econômico-financeiras como aquelas que versam sobre as concessões dos mencionados Títulos de Utilidade Pública 
(isenções fiscais para entidades religiosas), passando pela formatação de uma "consciência evangélica" ( Dia do Pastor Evangélico) pautada em leis aprovadas em plenário que tratam de uma "pauta moral e de costumes", até a edificação de objetos geográficos (monumentos à Bíblia) que cristalizam um "sistema de objetos e ações ${ }^{11 "}$ no território da Baixada Fluminense/RJ, só corroboram que atualmente o elemento religião é de fundamental importância à compreensão da política e do território, redimensionando-os e requalificandoos.

O espectro religioso encontra-se tão presente na estruturação da representação parlamentar de cunho evangélico/pentecostal na Baixada Fluminense/RJ que foi eloquente atestar, conforme demonstrou a tabela 2, que leis aprovadas em plenário diretamente relacionadas à religião ( 23 leis, 8,6\% do total) e aquelas que contemplam entidades religiosas através do expediente jurídico do título de "utilidade pública" ( 36 leis, 13,4\% do total) no município de Nova Iguaçu tido aqui como exemplo de investigação, somam juntas cerca de 1/5 da demanda legislativa total de uma Câmara Municipal de um município de quase 1 milhão de habitantes pertencente ao segundo estado mais rico e importante da federação. Por outro lado, de acordo com a mesma tabela 2, verifica-se que a representação parlamentar voltada para as questões que envolvem a cidadania, (ações afirmativas raciais, direitos da mulher, das crianças e idosos, das pessoas com deficiências) somam apenas 10,6\% do total de leis aprovadas, isto é, cerca da metade das leis que versam acerca da religião.

Ou ainda, caso se aceite a comparação das finalidades representativas parlamentares no tocante aos serviços sociais básicos, o fato demonstrado também na tabela 2, que as leis aprovadas concernentes aos direitos básicos de cidadania como a saúde (1,4\% do total de leis) e educação $(6,2 \%$ do total de leis) não alcancem nem a metade do interesse da representação parlamentar direcionada aos temas de interesse religioso, notadamente evangélico/pentecostal.

Desse modo, poder-se-ia mesmo afirmar que a representação política tem, nos tempos hodiernos no supracitado escopo territorial de análise, fortes e irrefutáveis conexões religiosas.

\section{REFERÊNCIAS}

AZEVEDO, Reinaldo. Brasil, o maior país católico do mundo, já é o maior país pentecostal. De quem é a culpa? 2020. VEJA. Disponível em:

\footnotetext{
${ }^{11}$ Referencial teórico do geógrafo Milton Santos (A Natureza do Espaço, 1996) que parte das noções de tempo, razão, técnica e emoção, indispensáveis ao entendimento do espaço geográfico em sua complexa estruturação.
} 
$<$ https://veja.abril.com.br/blog/reinaldo/brasil-o-maior-pais-catolico-do-mundo-ja-e-o-maiorpais-pentecostal-de-quem-e-a-culpa/> . Acesso em: 16 nov. 2020.

CIPRIANI, Gabriele. Pentecostalismo. Portal São Francisco. 2020. Disponível em: $<$ https://www.portalsaofrancisco.com.br/historiageral/pentecostalismo\#: :text=Pentecostalis mo\%20\%C3\%A9\%20como\%20se\%20chama,dom\%20de\%201\%C3\%ADnguas \%20(glossolal ia)>. Acesso em: 16 nov. 2020.

FIGUERÊDO, Maria Aparecida de. Gênese e (re) produção do espaço brasileiro na Baixada Fluminense. Revista Geo-Paisagem on line, Rio de Janeiro, ano 3, n. 5, 2004.

FILHO, Valdemar Figueredo. Entre o palanque e o púlpito: mídia, religião e política. São Paulo, Ed. Annablume, 2005.

FILHO, Valdemar Figueredo. O Evangelho segundo Bolsonaro. Revista Portal da Esquerda. 2019. Disponível em <https://www.cartamaior.com.br/?/Editoria/Politica/OEvangelho-segundo-Bolsonaro/4/43768>. Acesso em: 15 nov. 2020.

FRESTON, Paul Charles. Religião e Política, Sim; Igreja e Estado, Não. Editora Ultimato. Ano 2006.

IBGE. Instituto Brasileiro de Geografia e Estatística. Características étnico-raciais da população. 2014.2 Disponível em: <http://www.ibge.gov.br/home/estatistica/populacao/caracteristicas_raciais/default_raciais.sht m>. Acesso em: 02 ago. 2020.

MARIANO, Ricardo. Religião e política no Brasil: ocupação evangélica da esfera pública e laicidade. In: AVELAR, L.; CINTRA, A. O. (orgs) Sistema político Brasileiro: uma introdução. $3^{\text {a }}$ ed. São Paulo: Editora Unesp, 2015.

MARIANO, Ricardo. Neopentecostais: sociologia do novo pentecostalismo no Brasil. 2 ed. São Paulo: Edições Loyola, 2005.

RAMOS, A. e ZACARIAS, N. V. Neopentecostais e projeto de poder. Revista Le Monde Diplomatique Brasil, ed. 115, 2017. Disponível em: $<$ https://diplomatique.org.br/neopentecostais-e-o-projetode\%20poder/?fbclid=IwAR2Ij8bg9oy9XrQJ88jme1yl-UPP8PACTn0JhDvgC4j4a5_Db_HpxRHuuI>. Acesso em: 15 nov. 2020.

SANTOS, Milton. A Natureza do Espaço: técnica e tempo, razão e emoção. São Paulo: HUCITEC, 1996.

SELMÁN, Pablo. Quem são? Por que eles crescem? No que eles creem? Pentecostalismo e política na América Latina. Revista Nueva Sociedad. Argentina. 2019. Disponível em: <http://www.ihu.unisinos.br/78-noticias/588669-quem-sao-por-que-eles-crescem-no-queeles-creem-pentecostalismo-e-politica-na-america-latina>. Acesso em: 15 nov. 2020.

SIMÕES. Manoel Ricardo. A Cidade Estilhaçada: Reestruturação Econômica e Emancipações Municipais na Baixada Fluminense. 2006. Tese (Doutorado em Geografia) - 
Programa de Pós-graduação em Geografia, Universidade Federal Fluminense, Niterói, RJ, 2006.

Artigo recebido em: 15 de março de 2021.

Artigo aceito em: 18 de maio de 2021.

Artigo publicado em: 08 de junho de 2021. 